
\title{
$\begin{array}{ll}\text { Research Square } & \text { They should not be considered conclusive, used to i inform clinical practice, } \\ \text { or referenced by the media as validated information. }\end{array}$
}

\section{Exploring socioeconomic differences in receipt of resection for the primary lesion and time to resection for colon cancer in England: population-based study}

Mari Kajiwara Saito ( $\sim$ marisaito.Ishtm@gmail.com )

London School of Hygiene and Tropical Medicine Faculty of Epidemiology and Population Health https://orcid.org/0000-0003-3708-5039

Manuela Quaresma

London School of Hygiene and Tropical Medicine Faculty of Epidemiology and Population Health

Helen Fowler

London School of Hygiene and Tropical Medicine Faculty of Epidemiology and Population Health

Sara Benitez Majano

London School of Hygiene and Tropical Medicine Faculty of Epidemiology and Population Health

Bernard Rachet

London School of Hygiene and Tropical Medicine Faculty of Epidemiology and Population Health

Research article

Keywords: socioeconomic inequalities, cancer disparities, colon cancer, population-based data, cancer waiting times

Posted Date: June 22nd, 2020

DOI: https://doi.org/10.21203/rs.3.rs-37233/v1

License: (c) (i) This work is licensed under a Creative Commons Attribution 4.0 International License. Read Full License 


\section{Abstract}

Background A persistent socioeconomic gap in colon cancer survival is observed in England. Provision of cancer care may also vary by socioeconomic status (SES). We investigated population-based data to explore differential care by SES.

Methods We analysed a retrospective cohort of patients diagnosed with colon cancer in England (2010-2013) using the national cancer registry data. We examined potential factors associated with receipt of or time to resection and whether socioeconomic differences exist in these two outcomes using logistic and linear regressions. Multiple imputation was used for missing stage, tumour grade and emergency presentation (EP).

Results A total of 68169 colon cancer patients were analysed. In the most affluent group, $21.0 \%$ (3138/14917) had EP whereas 27.9\% (2901/10386) in the most deprived. Patients with higher age at diagnosis $(80<)$ and higher number of comorbidities had more than twice the odds of not receiving resection compared with the reference group (age $<65$, having no comorbidities). Contrary, patients with EP had approximately $40 \%$ reduced odds (adjusted odds ratio $0.61,95 \%$ confidence interval $\mathrm{Cl}$ 0.58-0.64) of not receiving resection compared with those without EP. We observed no socioeconomic variation in the receipt of resection in all stages. However, among a total of 45332 patients undergoing resection, the proportion of patients receiving urgent surgery (surgery before or within seven days of diagnosis) was higher in the most deprived group $(39.9 \%, 2685 / 6733)$ than the most affluent $(35.4 \%, 3595 / 10146, p<0.001)$. Days from diagnosis to resection ranged from $33.9(95 \% \mathrm{Cl} 33.1-34.8)$ in stage II to $38.2(95 \% \mathrm{Cl} 36.8-39.7)$ in stage I, but no socioeconomic differences in time were seen in all stages when patients were confined to those undergoing elective surgery (surgery more than seven days after diagnosis).

Conclusions Deprived groups tended to have higher proportions in EP and urgent surgery, which in part contributed to the apparent no socioeconomic variation in receipt of resection for all patients, nor time to treatment for patients undergoing elective surgery shown in this study. Other steps in care to reduce EP and urgent surgery should be considered to improve socioeconomic inequalities in colon cancer survival.

\section{Introduction}

Significant improvements in the survival of cancer have been achieved over the last two decades owing to developments in early diagnosis and treatment. However, inequalities in cancer survival remain both between and within countries [1]; survival varies by age [2], sex, ethnicity [3] and socioeconomic status (SES) $[4,5]$. Notably, socioeconomic inequalities in cancer survival have been observed in England despite the healthcare system based on universal health coverage. Particularly, survival of colon cancer varies widely based on socioeconomic deprivation. For example, a 7 to $10 \%$ difference in one-year relative survival for colon cancer has been reported in England between the most affluent and the most deprived members of society [6].

England had approximately 23000 new cases of colon cancer in 2017 (age-standardised incidence rate 51 in males and 40 in females per 100000 population), making it the fourth most prevalent cancer that year [7]. Death from colon cancer accounted for $5.5 \%$ of all cancer deaths in England and Wales, with the total number of deaths exceeding 8000 in 2017 [8, 9]. Survival of colon cancer depends not only on patient and tumour factors such as age, comorbidities and cancer stage, but also on how healthcare systems perform towards the patients. Timely and appropriate diagnosis and treatment, as well as the assessment of comorbidities are critical. Generally, for most patients with colon cancer, resection of the primary tumour remains the first and essential treatment.

The National Health Service (NHS) England has established several waiting time targets for colorectal cancer (CRC) care. Achievements in the waiting time targets are high. In 2018/19, the two-week wait for a specialist consultation following an urgent referral was achieved for $92.0 \%$ and $89.6 \%$ of people for all cancers and CRC, respectively [10]. In the same year, the 31-day wait target from diagnosis to the first treatment for all cancers and CRC was achieved in $96.8 \%$ and $97.3 \%$ of patients, respectively [10]. However, socioeconomic inequalities in survival remain and the variations in the utilisation of cancer care have not been well investigated. Whether the receipt of and time to treatment affect the socioeconomic gap in survival is poorly understood.

Based on the hypothesis that the healthcare system may differentially affect cancer survival for various sub-populations of the patients, we aim to explore socioeconomic variations in the receipt of major resection for the primary lesion and the time from diagnosis to resection for colon cancer in England. We examined potential factors associated with receipt of or time to major resection and investigated whether socioeconomic differences exist within these two outcomes.

\section{Methods}

\section{Data}

Residents of England, who were diagnosed with the first primary colon cancer between January 2010 and March 2013 and followed up until the end of 2014 , were included in the study. Inclusion criteria were colon cancer (coded by the International Classification of Diseases tenth version: ICD-10 with C18 excluding cancer of appendix) of any histological type and age at diagnosis of 15 to 99 . Tis (carcinoma in situ) was excluded from the analysis. Vital status, SES, date of birth, date of death, sex, tumour site (coded by ICD-10) and stage at diagnosis were obtained from the national cancer registry (Office for National Statistics: ONS) in England. Cancer site was categorised into four groups: right-sided colon (the ascending colon, hepatic flexure and caecum), transverse colon (the transverse colon and splenic flexure), left-sided colon (the descending and sigmoid colon) and overlapping or unspecified colon. These data were linked to Cancer Analysis System (CAS) data, National Bowel Cancer Audit (NBOCA) data and Hospital Episode Statistics (HES) data. Information on pathology (histology and tumour grade) were extracted from CAS data and each categorised into two groups (adenocarcinoma and others: tumour grade G1, G2 and G3, G4). Histology and tumour grade were included in the analysis to explore any biological variations among different SES groups. Information on the date of clinical diagnosis and clinical staging were recorded in NBOCA data. Information on treatment (date and type of procedures coded by the Office of Population Censuses and Surveys fourth version: OPCS-4, Classification of Interventions and Procedures) and comorbidities were recorded in HES data. 
Information on stage (the fifth edition of the UICC TNM Classification [11]) was derived through a restrictive approach using both the National Cancer Registry and NBOCA data [12]. Emergency presentation before the first surgical treatment for the primary lesion (i.e. emergency presentation recorded at the time of diagnosis or the time of the first treatment) was established from routes to diagnosis recorded in NBOCA data and supplemented by HES data [13]. The primary source of data regarding the extraction of the date and type of operation procedure of the first major resection was NBOCA but supplementary information was extracted from HES if NBOCA data did not contain a report on the operation. Data from NBOCA covered $82.0 \%$ of the total information on the first major resection. Types of operation that were identified as major resection for the primary lesion are: right hemicolectomy and extended right hemicolectomy, transverse colectomy, left hemicolectomy, sigmoid colectomy, proctocolectomy, panproctocoletcomy, total colectomy, total excision of colon, subtotal excision of colon +/- rectum, anterior resection, perineal resection and total exenteration of pelvis (see list of OPCS-4 codes in Additional file 1). Information on operation was extracted between 30 days prior to and 180 days after the date of diagnosis.

Seventeen comorbidities, defined in Charlson Index and obesity (body mass index: BMI > 30), which were recorded between five and zero years before the diagnosis of colon cancer, were extracted from HES based on an algorithm developed by Maringe, Fowler, Rachet and Luque-Fernandez [14-16]. The comorbidities were separately defined as chronic and acute comorbidities, based on their clinical relevance to the selection and timeliness of treatment for colon cancer (e.g. invasive or less invasive treatment, curative or palliative treatment). Comorbidities that appeared on HES at least once between half a year and five years before diagnosis were characterised as chronic comorbidities. Comorbidities that were recorded for the first time, between the date of diagnosis and half a year before diagnosis were characterised as acute comorbidities.

Of the 17 comorbidities, ten comorbidities that imply an irreversible condition of vital organs (brain, heart, lung, liver, kidney, immune system or vascular system) were selected as chronic comorbidities (see Additional file 2). Obesity was included independently in the acute phase only (zero to half a year before diagnosis) because BMI is a time-varying variable (i.e. reversible condition) and may confound with stage at diagnosis. Other 14 comorbidities were selected as acute comorbidities. Unlike the Charlson Index, the comorbidities were just counted but not assigned a weight (see Additional file 2).

Income domain of the Index of Multiple Deprivation (IMD 2010) quintile was used to derive information on the deprivation level of patients based on their residence at the time of cancer diagnosis. This index is an ecological measure defined at lower-layer super output area level (1,500 inhabitants on average).

\section{Analysis strategy}

The first analysis explored socioeconomic differences in receipt of resection. To measure appropriate cancer care, the outcome in the first analysis was set as whether a patient received major resection for the primary lesion ( 0 yes, 1 no), and logistic regression was used. The second analysis examined whether timely cancer care was provided equally to all SES groups. The outcome in the second analysis was the number of days from diagnosis to surgical treatment (major resection for the primary lesion), and linear regression was used.

A priori exposure was SES. In both analyses using logistic and linear regression, bivariable analyses with SES as a priori interest were first conducted to assess the changes in the association between SES and outcome (i.e. the confounding effect of each variable). Each variable was also retained in the multivariable analysis based on the Wald test $(p<0.05)$ of the bivariable analysis. The Wald test was used instead of the likelihood ratio test to account for the uncertainty in imputed data [17]. Variables were finally selected by backward elimination. A removed variable was added to the multivariable model again as a confounder if a model with the variable changed the effect of SES (e.g. odds ratio: OR of the most deprived in the first analysis) by more than 10\%. Age group and sex were kept as a priori confounders and an interaction term between SES and stage was added as the main interest.

The main analyses were conducted with multiply imputed data because the critical information (stage, tumour grade and emergency presentation) was missing. The stage was missing for $30.6 \%$ of the total cases, tumour grade for $24.2 \%$ and emergency presentation for $9.9 \%$. These three variables and histology (missing for less than 3\%) were imputed 30 times using multiple imputations by chained equations after the mechanisms of missingness in all three variables were examined to have missingness at random dependent on covariates and outcome [17]. For the imputation, the variables used were sex, age group, cancer site, number of chronic and acute comorbidities, receipt of major resection, vital status, Nelson-Aalen estimator and government office region. The distributions of the imputed stage, histology, tumour grade and emergency presentation are shown in Additional file 3. Results of the complete-case analyses (i.e. without imputations) are shown in Additional files 4 to 7.

In the second analysis, patients who received resection within seven days of diagnosis were defined as having received an urgent surgery and were excluded from the analysis. We included patients who underwent elective surgery (i.e. received resection after eight days or more from diagnosis) only in the analysis because undergoing an urgent surgery could mean that the patient did not receive an adequate assessment of cancer stage and comorbidities. The outcome in days was log-transformed because the distribution of the days from diagnosis to treatment was right-skewed. After the log-transformation, the outcome was normally distributed.

\section{Results}

A total of 68169 patients were diagnosed with colon cancer between January 2010 and March 2013. Four patients were excluded because they did not have a record on comorbidities in HES data. Over half of the patients were male (52.8\%), and the median age at diagnosis was 74.1 years. Socioeconomic gradients towards better figures in the most affluent group were noticeable in the proportion of patients with emergency presentation and the number of both chronic and acute comorbidities (Table 1). There was no clear socioeconomic trend in stage distribution, histology and tumour grade, but the missingness in tumour grade was higher in more deprived groups. 
When patients with or without major resection were compared, the percentage of those receiving resection was lower in more deprived groups than the most affluent group (68.0\% in the most affluent group, $64.8 \%$ in the most deprived). Median age at diagnosis was approximately five years higher among the patients without resection. Approximately $90 \%$ of the patients with stage II or III cancer underwent major resection. Sex and emergency presentation did not affect receipt of resection when not adjusted for other factors. A smaller proportion of patients underwent resection as the number of chronic and acute comorbidities increased (Table 1).

\section{Receipt of resection}

All examined factors except histology were associated with receipt of major resection (Table 2). To show the overall change in the effect of SES, the adjusted ORs of SES in Table 2 were based on a model without interaction between SES and stage. For other variables, adjusted ORs were based on the multivariable model with interaction between SES and stage (final model). Age of $80+$ had approximately three times the odds of not receiving resection compared with the patients aged under 65 years after adjusting for other factors. Patients with an emergency presentation had an approximately $40 \%$ lower adjusted odds of not receiving resection than those without an emergency presentation. Patients with an increased number of chronic and acute comorbidities had higher adjusted odds of not receiving resection than those without comorbidities.

No factors in the bivariable analyses cancelled the socioeconomic gradient that favoured the most affluent patients in the receipt of major resection. The gradient was slightly weakened when stage was adjusted in the bivariable analysis. Chronic and acute comorbidities also weakened the gradient, but age worsened it. The reduction in gradient made by acute comorbidities was smaller than that made by chronic comorbidities. Cancer site and emergency presentation reduced the impact of SES on non-receipt of resection.

The multivariable analyses stratified on stage showed that the most deprived group had higher adjusted odds of not receiving resection for stages II and III compared with the most affluent group. However, for both stages, the figures were not statistically significant (Table 3). In other stages, the socioeconomic gradient was weak and without a statistical significance. Complete-case analyses showed similar trends (Additional file 5).

\section{Time from diagnosis to major resection for patients with elective surgery}

Among the 45332 patients ( $66.5 \%$ of the total) with colon cancer who received major resection, 13574 patients underwent resection before the diagnosis ( 30 to zero days before the diagnosis) and 3306 patients underwent resection within seven days of diagnosis. These patients (a total of $16880,37.2 \%$ of the patients who received major resection) were removed from the analysis.

When the 16880 patients with urgent surgery and the 28452 with elective surgery were further compared, the percentage of those undergoing urgent surgery was higher in the deprived groups than the most affluent group (Table 4, 35.4\% in the most affluent group, 39.9\% in the most deprived, $p<0.001$ ). Additional analysis revealed that the socioeconomic gradient in those with urgent surgery was largely confounded by emergency presentation. Of the patients who had an emergency presentation, 4574 (29.6\%) had stage IV cancer.

When the 31-day waiting time target for receipt of treatment (defined here as a resection of the primary lesion) was compared, the target time was achieved more in the deprived groups (Table 4, 59.7\% in the most affluent group, $63.6 \%$ in the most deprived, $\mathrm{p}<0.001$ ). This paradoxical association remained when the achievement in the time target was compared among the patients undergoing elective surgery only; however, the absolute difference between the most affluent and the most deprived groups dropped from $3.9 \%$ to $1.9 \%$ (Table 4 ).

In the bivariable analysis excluding the 16880 patients with urgent surgery, there was no evidence that the number of days from diagnosis to treatment differed by SES. The mean days from diagnosis to treatment was $36.3(95 \% \mathrm{Cl} 35.8,36.8)$ in the most affluent patients as a reference group (geometric mean of days, reference meaning 'intercept' days in bivariable analysis, Table 5).

All factors except the year of diagnosis and presence of obesity were associated with time to treatment. Histological type, emergency presentation and the number of comorbidities influenced the time to treatment to a relatively large magnitude.

When adjusted for all other variables, females had a $3 \%$ shorter time from diagnosis to treatment than males. In the bivariable analysis, age was associated with time to treatment in a quadratic term, but in the multivariable analysis the association was linear rather than quadratic ( $p=0.43$, likelihood ratio test comparing quadratic and linear terms in complete cases) or categorised group. For every 10 -year increase in age from the mean of 72.6 , the number of days increased by $2 \%$ ( $\beta$ as a coefficient, $e^{\beta} 1.02$ in multivariable regression). The histological type of non-adenocarcinoma and left-sided colon was associated with a longer time interval to resection. The increase in time to treatment was approximately 13 to $16 \%$ depending on the differences in each factor. Patients with stages II, III and IV had approximately $10 \%$ shorter time interval than those with stage I cancer. With an emergency presentation, time from diagnosis to treatment was shortened by approximately $13 \%$ despite the exclusion of patients undergoing urgent surgery within seven days of diagnosis. The presence of both chronic and acute comorbidities also contributed to an up to approximately $15 \%$ increase in the time interval to treatment.

Stage-specific ratios of time to treatment by SES group are displayed in Table 6 . The mean number of days from diagnosis to treatment in the reference group (the most affluent group) are also shown by each stage, derived by multivariable models with interaction between SES and stage. The mean days from diagnosis to treatment in the reference group ranged from 33.9 for stage II to 38.2 for stage I after adjusting for all other factors, but the number of days did not differ by SES for all stages. There was no evidence of a socioeconomic trend in time to treatment in the complete-case analyses.

\section{Discussion}




\section{Summary of findings and interpretation}

We observed a socioeconomic trend in the receipt of major resection favouring the most affluent patients for stages II and III cancer but it was not statistically significant $(p>0.05)$. Patients with older age, left-sided colon, non-adenocarcinoma, a higher number of comorbidities and non-obese groups had higher odds of not undergoing resection when compared with the reference group. Patients with emergency presentation had approximately $40 \%$ lower odds of not receiving resection.

We also found that the percentage of patients undergoing urgent surgery was higher in the deprived groups than in the most affluent group; seemingly, the waiting time target of providing treatment within 31 days of diagnosis was achieved more in the deprived groups. The mean time to surgical treatment was approximately 38 days when the patients undergoing urgent surgery were removed. No socioeconomic disparities were observed for the time to treatment when patients were confined to those undergoing elective surgery. Patients with non-adenocarcinoma or having 2+ comorbidities experienced a longer time to treatment than patients with adenocarcinoma or those with no comorbidities.

There were no clear socioeconomic differences in the receipt of major resection. However, cautious interpretation is needed. Among patients with stage I or IV cancer, not undergoing major resection does not necessarily mean inappropriate care. For some patients with stage I cancer, having only an endoscopic resection (e.g. endoscopic mucosal resection or endoscopic submucosal dissection) alone can be a sufficient treatment option intending cure. There was no information on whether the stage I patients had unfavourable histological findings, and data regarding why major resection was not performed were mostly missing. Similarly, for patients with stage IV, there was little information on why major resection was not performed. In stage IV, indication for the major resection of the primary lesion largely depends on clinical factors (e.g. performance status, the severity of obstruction or bleeding symptoms, whether the patient reacted to chemotherapy aiming conversion therapy and the extent of metastasis to other organs) that are not fully captured in the population data. Neither palliative nor curative intent was clear among the patients with stage IV cancer. Misclassification of the outcome could occur because of the aforementioned reasons. At this point, therefore, the results may only be interpreted with certainty for patients with stage II or III cancer, who have the potential to be cured if treated appropriately.

As the cancer locates more distal, the odds of not receiving resection increased. For some reason, right-sided colon cancers were selected for resection. One potential reason is that the patients with more distal cancer may be diagnosed with more obvious symptoms such as obstruction. These patients may have died immediately after the diagnosis, before undergoing resection. Similarly, patients with higher tumour grades (G3/G4) may have died before resection because their tumours were more aggressive than those of lower grades (G1/G2). While patients with 2+ chronic comorbidities had more than three times higher odds of not undergoing resection compared with those without chronic comorbidities, patients with 2+ acute comorbidities had only twice the odds of not receiving resection compared with those without acute comorbidities. Chronic comorbidities, which we confined to ten comorbidities with irreversible damages of vital organs, may have affected the decisions regarding treatment more importantly than the acute comorbidities. Instead, patients with a higher number of chronic comorbidities might be more likely to die before resection. This situation may also imply that current care lacks proper guidelines for the simultaneous management of chronic multimorbidity [18]. Another possible explanation is that patients with a larger number of acute comorbidities rather reflect the receipt of appropriate care. They may have received thorough screenings for other diseases, such as underlying cancer, and were therefore diagnosed and operated for the colon cancer.

Regarding time to treatment, we found no socioeconomic variations in the number of days from diagnosis to resection for all stages when patients were restricted to those with elective surgery. Socioeconomic differences in time to treatment have been investigated in many other studies [19-26]. However, the reported outcome varies by study (e.g. outcomes shown in days, hazard ratios or odds ratios at a certain cut-off-time). The definition of the treatment (e.g. any treatment, major resection only, chemotherapy or radiotherapy) also differs by study. As in line with the previous reviews on time to treatment [27, 28], there is a wide diversity in the definition of 'delay'.

Our study demonstrated that one of the waiting time targets, providing treatment within 31 days of diagnosis, was achieved in higher proportions among the deprived groups as with a larger proportion of more deprived patients undergoing urgent surgery. Considering that the presence of emergency presentation confounded urgent surgery, achievement in the waiting time target may not necessarily reflect a high quality of cancer care.

One systematic review identified an equivocal association between time to treatment and survival [27]. We did not examine this association in the present study. However, like a previous report [29], persistent socioeconomic inequalities in survival, alongside our findings of no socioeconomic variation in time to treatment for patients with elective surgery, may suggest that achieving some waiting time targets is not related to better survival. Rather, a noteworthy point in assessing colon cancer care might be the high number of deprived patients experiencing emergency presentation and urgent surgery. It is known that healthseeking behaviours, screening uptake and access barriers to healthcare may influence emergency presentation [28, 30]. Some up-stream factors are not easily modifiable but improving access to healthcare system may reduce the emergency presentation. Evidence suggests that emergency presentation is low in screening participants [31] and that screening uptake is low amongst deprived groups [32]. The situation observed here might be because of the 'inverse equity law' [33]. Low screening uptake in the deprived groups may be partly attributable to the high emergency presentation amongst the population and, subsequently, to poorer survival [34,35]. Another potential barrier in healthcare access could be quality postoperative care. Deprived groups tend to have worse short-term postoperative mortality [36, 37]. However, when provided care was equalised for all SES groups, a socioeconomic gap in survival was not observed [38]. These findings support our hypothesis that the survival gap may be partly explained by access inequalities in cancer care, particularly the postoperative care. Deprived patients may be referred to hospitals with less specialised or less experienced doctors and may therefore suffer from poorer survival. Future studies should focus on identifying the bottleneck of care through decomposing patient pathways to modify access inequalities.

\section{Strength and limitations}


The strength of our study is that, through the use of the national cancer registry data linked with clinical information from HES, we provided an overall picture of how patient factors (age, sex and comorbidities) and tumour factors (site, stage, histology and tumour grade) interacts with the performance of healthcare system at the national level. Our analyses also included crucial tumour factors, i.e. not only stage but also histology and tumour grades. One limitation is that the difference by SES for some histological types (mucinous, signet-cell carcinoma versus other adenocarcinomas) was not explored. This was because the majority were recorded without detailed histological information (i.e. recorded as adenocarcinoma), and $12.6 \%$ of the total cases were recorded as having neoplasm or carcinoma. Patients with histological types of neoplasm or carcinoma were grouped into patients with adenocarcinoma under the assumption that the majority of the colon cancer cases are likely to have adenocarcinoma. Thus, misclassification may exist.

For the first analysis, other potential outcomes that may reflect the performance of a healthcare system are the percentage of patients who received major resection for curative intent, the number of lymph nodes yielded, postoperative complications or failure-to-rescue rate [25, 39-45]. These measures were not used because the missingness was substantial for those outcomes.

When analysing time to treatment, patients who received urgent surgery were removed. The urgent surgery was defined as an operation performed within seven days of diagnosis. This cut-off in days may be arbitrary, but while the patients receiving resection within three days of diagnosis exceeded $29 \%$ of those who received resection, only $2.1 \%$ underwent resection four to seven days from the date of diagnosis. Therefore, the cut-off of the number of days with which an urgent surgery is defined is considered to make little change in the results.

Another limitation is that our study did not consider random effects due to a $10 \%$ missingness in hospital information. Both receipt of resection and time to treatment may be affected by differences in patient characteristics, which are also likely to vary among hospitals.

Although there was no socioeconomic difference in the time from diagnosis to treatment, the time from recognition of symptoms to diagnosis could be longer in the deprived groups due to differences in health-seeking behaviour. Time to diagnosis, otherwise called the 'appraisal interval' and 'help-seeking interval' [28], was not incorporated in our analysis. These time lengths may differ by SES and could lead to socioeconomic inequalities in survival.

\section{Implication for cancer policy}

We found no socioeconomic differences in the receipt of resection for all patients with colon cancer. However, a more substantial proportion of patients in the deprived groups seemed to have undergone emergency presentation and urgent surgery than the most affluent group. The paradox for observing no socioeconomic variation in receiving resection is that the emergency presentation worked protective against the failure to receive resection. The presence of emergency presentation also worked positively for achieving the waiting time target of treatment within 31 days of diagnosis. Time from diagnosis to treatment was equally distributed among different SES groups only if patients were limited to those with elective surgery. Identification of other potential reasons for survival inequalities is needed, particularly focusing on what happens before and after patients receive resection. Examples include an investigation into access before diagnosis to reduce high emergency presentation and urgent operation, an assessment of the quality of postoperative care by SES, such as an exploration of complication rates or failure-to-rescue rates by SES, and inspection of within and between-hospital variations in these outcomes. Further evaluation of the receipt of treatment, such as differences in the receipt of chemotherapy and radiotherapy by SES, may also be worth investigating.

\section{Conclusions}

Major resection for the primary lesion seems to be equally provided for different SES groups. Among the patients with major resection, $62.8 \%$ received elective surgery. When confined to those with elective surgery, there was no difference in the time from diagnosis to resection. However, the higher percentage of deprived patients with emergency presentation and urgent resection suggests that the initial steps of cancer care, diagnosis and first treatment maybe not equally accessed by different SES groups. Other potential causes should be sought to disentangle the mechanisms of socioeconomic inequalities in colon cancer survival.

\section{Abbreviations}




\begin{tabular}{ll} 
BMI & body mass index \\
\hline CAS & Cancer Analysis System \\
\hline CRC & colorectal cancer \\
\hline HES & Hospital Episode Statistics \\
\hline ICD-10 & International Classification of Diseases tenth version \\
\hline IMD & Index of Multiple Deprivation \\
\hline NBOCA & National Bowel Cancer Audit \\
\hline NHS & National Health Service \\
\hline ONS & Office for National Statistics \\
\hline OPCS-4 & Office of Population Censuses and Surveys fourth version \\
\hline OR & odds ratio \\
\hline SES & socioeconomic status
\end{tabular}

\section{Declarations}

\section{Ethics approval, consent to participate and consent for publication}

All ethics and statutory approvals for data access and analyses have been obtained by the Cancer Survival Group (London School of Hygiene and Tropical Medicine Ethics Reference 11984).

\section{Availability of data and materials}

Data were provided by Public Health England (PHE). Our data sharing agreement with PHE clearly stipulates that they cannot be shared with any third party without the prior written consent of PHE.

\section{Competing interests}

The authors declare no conflicts of interest.

\section{Funding}

MKS receives no funding. MQ, HF and SBM are funded by Cancer Research UK (C7923/A29018).

\section{Authors' contributions}

Conceptualisation: MKS BR. Data analysis: MKS. Writing the paper: MKS MQ HF SBM BR.

\section{Acknowledgements}

We would like to thank all patients registered in the national cancer registry data. MKS is a scholar of the British Council Japan Association. Contents of this paper were published as a part of MKS's PhD thesis with a modification of study population [46].

\section{Author information}

\section{Affiliations}

Department of Non-communicable Disease Epidemiology, Faculty of Epidemiology and Population Health, London School of Hygiene \& Tropical Medicine, Keppel Street, London, WC1E 7HT, UK

Mari Kajiwara Saito, Manuela Quaresma, Helen Fowler, Sara Benitez Majano, Bernard Rachet

\section{References}

1. Allemani C, Matsuda T, Di Carlo V, Harewood R, Matz M, Niksic M, et al. Global surveillance of trends in cancer survival 2000-14 (CONCORD-3): analysis of individual records for 37513025 patients diagnosed with one of 18 cancers from 322 population-based registries in 71 countries. Lancet. 2018;391(10125):1023-75.

2. Li M, Morrell S, Creighton N, Tervonen H, You H, Roder D, et al. Has cancer survival improved for older people as for younger people? New South Wales, 1980-2012. Cancer Epidemiol. 2018;55:23-9.

3. Zeng C, Wen W, Morgans AK, Pao W, Shu XO, Zheng W. Disparities by Race, Age, and Sex in the Improvement of Survival for Major Cancers: Results From the National Cancer Institute Surveillance, Epidemiology, and End Results (SEER) Program in the United States, 1990 to 2010. JAMA Oncol. 2015;1(1):8896. 
4. Schrijvers CTM, Coebergh JWW, Vanderheijden LH, Mackenbach JP. Socioeconomic Variation in Cancer Survival in the Southeastern Netherlands, 19801989. Cancer. 1995;75(12):2946-53.

5. Dalton SO, Schuz J, Engholm G, Johansen C, Kjaer SK, Steding-Jessen M, et al. Social inequality in incidence of and survival from cancer in a populationbased study in Denmark, 1994-2003: Summary of findings. Eur J Cancer. 2008;44(14):2074-85.

6. Rachet B, Ellis L, Maringe C, Chu T, Nur U, Quaresma M, et al. Socioeconomic inequalities in cancer survival in England after the NHS cancer plan. Br J Cancer. 2010;103(4):446-53.

7. Office for National Statistics. Cancer registration statistics, England: 2017. London: 2019 [accessed 30/03/2020]. Available from: https://www.ons.gov.uk/peoplepopulationandcommunity/healthandsocialcare/conditionsanddiseases/bulletins/cancerregistrationstatisticsengland/201

8. Macmillan Cancer Support. Statistics fact sheet. London; 2019.

9. Office for National Statistics. Death Registrations Summary Statistics, England and Wales, 2017. London: 2019 [accessed 30/03/2020]. Available from: https://www.ons.gov.uk/file?

uri=/peoplepopulationandcommunity/birthsdeathsandmarriages/deaths/datasets/deathregistrationssummarytablesenglandandwalesreferencetables/20

10. NHS England. Waiting Times for Suspected and Diagnosed Cancer Patients 2018-19 Annual Report. London 2019.

11. International Union Against Cancer (UICC) TNM Classification of Malignant Tumours. 5th ed. Sobin L, Wittekind C, editors. New York: Wiley-Liss; 1997.

12. Benitez-Majano S, Fowler H, Maringe C, Di Girolamo C, Rachet B. Deriving stage at diagnosis from multiple population-based sources: colorectal and lung cancer in England. Br J Cancer. 2016;115(3):391-400.

13. Elliss-Brookes L, McPhail S, Ives A, Greenslade M, Shelton J, Hiom S, et al. Routes to diagnosis for cancer - determining the patient journey using multiple routine data sets. $\mathrm{Br} \mathrm{J}$ Cancer. 2012;107(8):1220-6.

14. Maringe $\mathrm{C}$, Fowler H, Rachet B, Luque-Fernandez MA. Reproducibility, reliability and validity of population-based administrative health data for the assessment of cancer non-related comorbidities. PLoS One. 2017;12(3):e0172814.

15. Charlson ME, Pompei P, Ales KL, Mackenzie CR. A New Method of Classifying Prognostic Co-Morbidity in Longitudinal-Studies - Development and Validation. J Chron Dis. 1987;40(5):373-83.

16. Elixhauser A, Steiner C, Harris DR, Coffey RN. Comorbidity measures for use with administrative data. Med Care. 1998;36(1):8-27.

17. Van Buuren S. Analysis of imputed data. In: Van Buuren S, editor. Flexible Imputation of Missing Data. 2nd ed. Florida: CRC Press; 2018.

18. Tinetti ME, Fried TR, Boyd CM. Designing health care for the most common chronic condition-multimorbidity. JAMA. 2012;307(23):2493-4.

19. Moriceau G, Bourmaud A, Tinquaut F, Oriol M, Jacquin J-P, Fournel P, et al. Social inequalities and cancer: can the European deprivation index predict patients' difficulties in health care access? a pilot study. Oncotarget. 2016;7(1):1055-65.

20. Neal RD, Allgar VL. Sociodemographic factors and delays in the diagnosis of six cancers: analysis of data from the 'National Survey of NHS Patients: Cancer'. Br J Cancer. 2005;92(11):1971-5.

21. Porter GA, Inglis KM, Wood LA, Veugelers PJ. Access to care and satisfaction in colorectal cancer patients. World J Surg. 2005;29(11):1444-51.

22. Bardell T, Belliveau P, Kong W, Mackillop WJ. Waiting times for cancer surgery in Ontario: 1984-2000. Clin Oncol (R Coll Radiol). 2006;18(5):401-9.

23. Campbell NC, Elliott AM, Sharp L, Ritchie LD, Cassidy J, Little J. Impact of deprivation and rural residence on treatment of colorectal and lung cancer. Br J Cancer. 2002;87(6):585-90.

24. Jorgensen ML, Young JM, Dobbins TA, Solomon MJ. Predictors of variation in colorectal cancer care and outcomes in New South Wales: a populationbased health data linkage study. Med J Aust. 2014;200(7):403-7.

25. Paterson HM, Mander BJ, Muir P, Phillips HA, Wild SH. Deprivation and access to treatment for colorectal cancer in southeast Scotland $2003-2009$. Colorectal Dis. 2014;16(2):051-07.

26. Lejeune C, Sassi F, Ellis L, Godward S, Mak V, Day M, et al. Socio-economic disparities in access to treatment and their impact on colorectal cancer survival. Int J Epidemiol. 2010;39(3):710-7.

27. Ramos M, Esteva M, Cabeza E, Campillo C, Llobera J, Aguilo A. Relationship of diagnostic and therapeutic delay with survival in colorectal cancer: a review. Eur J Cancer. 2007;43(17):2467-78.

28. Walter F, Webster A, Scott S, Emery J. The Andersen Model of Total Patient Delay: a systematic review of its application in cancer diagnosis. J Health Serv Res Policy. 2012;17(2):110-8.

29. Di Girolamo C, Walters S, Gildea C, Benitez Majano S, Rachet B, Morris M. Can we assess Cancer Waiting Time targets with cancer survival? A populationbased study of individually linked data from the National Cancer Waiting Times monitoring dataset in England, 2009-2013. PLoS One. 2018;13(8):e0201288.

30. Zhou Y, Abel GA, Hamilton W, Pritchard-Jones K, Gross CP, Walter FM, et al. Diagnosis of cancer as an emergency: a critical review of current evidence. Nat Rev Clin Oncol. 2017;14(1):45-56.

31. Scholefield JH, Robinson MH, Mangham CM, Hardcastle JD. Screening for colorectal cancer reduces emergency admissions. Eur J Surg Oncol. 1998;24(1):47-50.

32. von Wagner C, Baio G, Raine R, Snowball J, Morris S, Atkin W, et al. Inequalities in participation in an organized national colorectal cancer screening programme: results from the first 2.6 million invitations in England. Int J Epidemiol. 2011;40(3):712-8.

33. Hart JT. The inverse care law. Lancet. 1971;1(7696):405-12.

34. McPhail S, Elliss-Brookes L, Shelton J, Ives A, Greenslade M, Vernon S, et al. Emergency presentation of cancer and short-term mortality. Br J Cancer. 2013;109(8):2027-34. 
35. McArdle CS, Hole DJ. Emergency presentation of colorectal cancer is associated with poor 5-year survival. Br J Surg. 2004;91(5):605-9.

36. Morris EJA, Taylor EF, Thomas JD, Quirke P, Finan PJ, Coleman MP, et al. Thirty-day postoperative mortality after colorectal cancer surgery in England. Gut. 2011;60(6):806-13.

37. Oliphant R, Nicholson GA, Horgan PG, Molloy RG, McMillan DC, Morrison DS, et al. Deprivation and Colorectal Cancer Surgery: Longer-Term Survival Inequalities are Due to Differential Postoperative Mortality Between Socioeconomic Groups. Ann Surg Oncol. 2013;20(7):2132-9.

38. Lyratzopoulos G, Sheridan GF, Michie HR, McElduff P, Hobbiss JH. Absence of socioeconomic variation in survival from colorectal cancer in patients receiving surgical treatment in one health district: cohort study. Colorectal Dis. 2004;6(6):512-7.

39. Almoudaris AM, Burns EM, Mamidanna R, Bottle A, Aylin P, Vincent C, et al. Value of failure to rescue as a marker of the standard of care following reoperation for complications after colorectal resection. Br J Surg. 2011;98(12):1775-83.

40. Silber JH, Williams SV, Krakauer H, Schwartz JS. Hospital and patient characteristics associated with death after surgery. A study of adverse occurrence and failure to rescue. Med Care. 1992;30(7):615-29.

41. Manilich E, Vogel JD, Kiran RP, Church JM, Seyidova-Khoshknabi D, Remzi FH. Key Factors Associated With Postoperative Complications in Patients Undergoing Colorectal Surgery. Dis Colon Rectum. 2013;56(1):64-71.

42. Rollet Q, Bouvier V, Launay L, De Mil R, Launoy G, Dejardin O, et al. No effect of comorbidities on the association between social deprivation and geographical access to the reference care center in the management of colon cancer. Dig Liver Dis. 2018;50(3):297-304.

43. Harris AR, Bowley DM, Stannard A, Kurrimboccus S, Geh Jl, Karandikar S. Socioeconomic deprivation adversely affects survival of patients with rectal cancer. Br J Surg. 2009;96(7):763-8.

44. Tilney H, Lovegrove RE, Smith JJ, Thompson MR, Tekkis PP, Britain ACG. The National Bowel Cancer Project: Social Deprivation Is an Independent Predictor of Nonrestorative Rectal Cancer Surgery. Dis Colon Rectum. 2009;52(6):1046-53.

45. Del Paggio JC, Nanji S, Wei X, MacDonald PH, Booth CM. Lymph node evaluation for colon cancer in routine clinical practice: a population-based study. Curr Oncol. 2017;24(1):E35-E43.

46. Saito M. Socioeconomic inequalities in colorectal cancer survival in England and Japan [PhD thesis]. London: London School of Hygiene and Tropical Medicine; 2019. doi: https://doi.org/10.17037/PUBS.04654954

\section{Supplementary Information}

Additional file 1. Operation code and name for colon cancer.

Additional file 2. Definition of chronic and acute comorbidities.

Additional file 3. Distribution after imputation (stage, histology, tumour grade, emergency presentation).

Additional file 4. Odds ratios of not receiving major resection by logistic regression, complete cases $(n=38070)$.

Additional file 5. Adjusted stage-specific odds ratios of not receiving major resection with interaction between SES and stage, complete cases ( $\mathrm{n}=38 \mathrm{070}$ ).

Additional file 6. Reference number of days and ratios for time from diagnosis to major resection by linear regression, complete cases including patients with elective surgery only $(n=20714)$.

Additional file 7. Adjusted stage-specific ratios and reference number of days from diagnosis to major resection by multivariable linear regression with interaction between SES and stage, complete cases including patients with elective surgery only $(n=20714)$.

\section{Tables}

Table 1 Baseline characteristics of colon cancer patients by socioeconomic status and receipt of major resection 


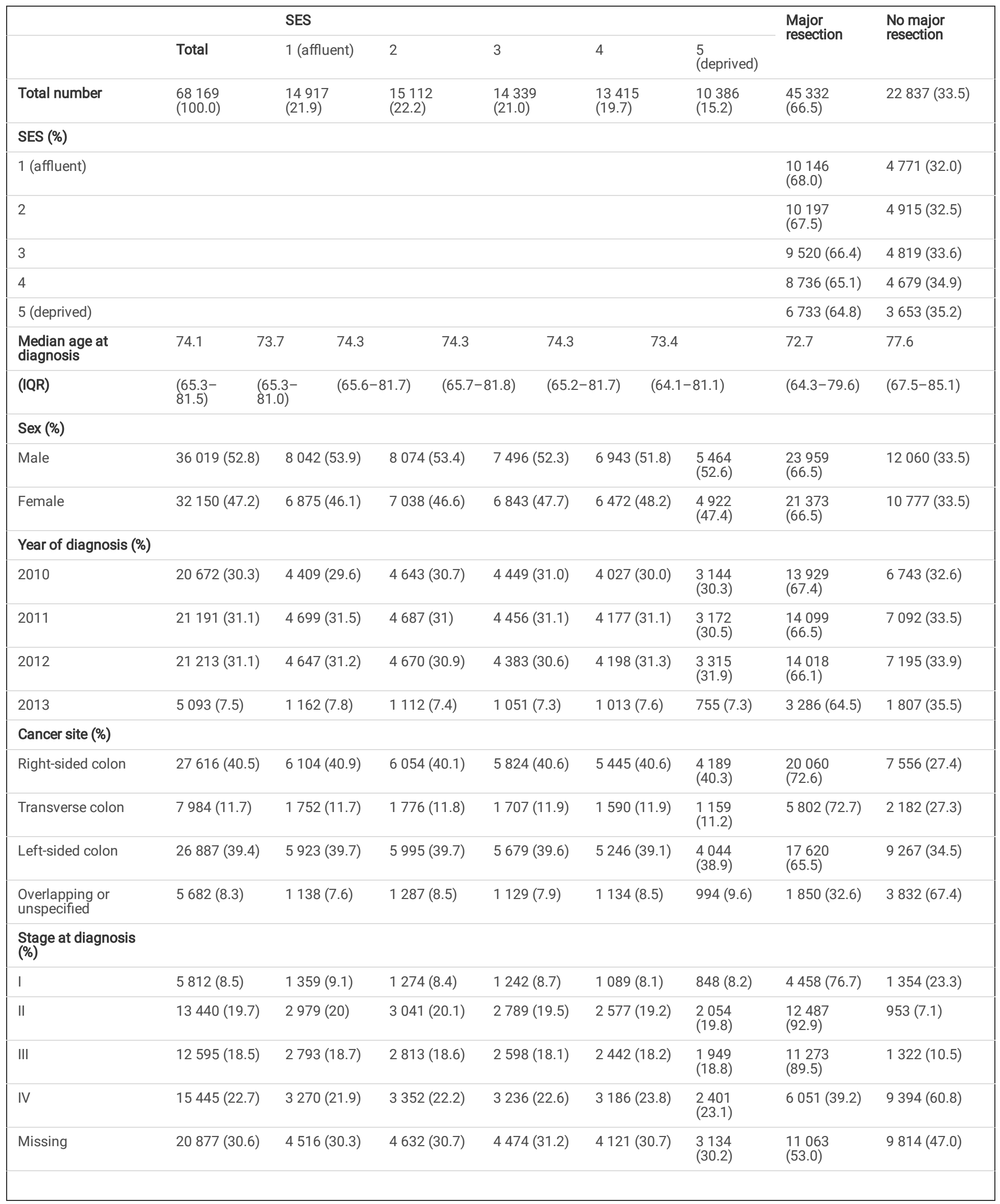

Continued from Table 1 


\begin{tabular}{|c|c|c|c|c|c|c|c|c|}
\hline & \multicolumn{6}{|c|}{ SES } & \multirow{2}{*}{$\begin{array}{l}\text { Major } \\
\text { resection }\end{array}$} & \multirow{2}{*}{$\begin{array}{l}\text { No major } \\
\text { resection }\end{array}$} \\
\hline & Total & 1 (affluent) & 2 & 3 & 4 & 5 (deprived) & & \\
\hline \multicolumn{9}{|l|}{ Histology (\%) } \\
\hline Adenocarcinoma & $\begin{array}{l}66024 \\
(96.9)\end{array}$ & $\begin{array}{l}14413 \\
(96.6)\end{array}$ & $\begin{array}{l}14635 \\
(96.8)\end{array}$ & $\begin{array}{l}13858 \\
(96.7)\end{array}$ & $\begin{array}{l}13035 \\
(97.2)\end{array}$ & $\begin{array}{l}10083 \\
(97.1)\end{array}$ & $44003(66.7)$ & $22021(33.4)$ \\
\hline $\begin{array}{l}\text { Non- } \\
\text { adenocarcinoma }\end{array}$ & $565(0.8)$ & $116(0.8)$ & $128(0.9)$ & $120(0.8)$ & $105(0.8)$ & $96(0.9)$ & $346(61.2)$ & $219(38.8)$ \\
\hline Missing & $1580(2.3)$ & $388(2.6)$ & $349(2.3)$ & $361(2.5)$ & $275(2.1)$ & $207(2.0)$ & $983(62.2)$ & $597(37.8)$ \\
\hline \multicolumn{9}{|l|}{ Tumour grade (\%) } \\
\hline $\mathrm{G} 1, \mathrm{G} 2$ & $\begin{array}{l}41998 \\
(61.6)\end{array}$ & 9472 (63.5) & $9449(62.5)$ & $8758(61.1)$ & $8100(60.4)$ & $6219(59.9)$ & 34231 (81.5) & 7767 (18.5) \\
\hline G3, G4 & $9655(14.2)$ & $2221(14.9)$ & $2142(14.2)$ & $2081(14.5)$ & $1811(13.5)$ & $1400(13.5)$ & $7633(79.1)$ & $2022(20.9)$ \\
\hline Missing & $\begin{array}{l}16516 \\
(24.2)\end{array}$ & 3224 (21.6) & $3521(23.3)$ & $3500(24.4)$ & $3504(26.1)$ & $2767(26.6)$ & $3468(21.0)$ & $13048(79.0)$ \\
\hline \multicolumn{9}{|c|}{ Emergency presentation (\%) } \\
\hline No & $\begin{array}{l}45320 \\
(66.5)\end{array}$ & $\begin{array}{l}10289 \\
(69.0)\end{array}$ & $\begin{array}{l}10216 \\
(67.6)\end{array}$ & 9678 (67.5) & 8705 (64.9) & $6432(61.9)$ & 33202 (73.3) & $12118(26.7)$ \\
\hline Yes & $\begin{array}{l}16122 \\
(23.7)\end{array}$ & $3138(21.0)$ & $3368(22.3)$ & 3329 (23.2) & $3386(25.2)$ & 2901 (27.9) & $11840(73.4)$ & $4282(26.6)$ \\
\hline Missing & $6727(9.9)$ & $1490(10.0)$ & $1528(10.1)$ & $1332(9.3)$ & $1324(9.9)$ & $1053(10.1)$ & $290(4.3)$ & 6437 (95.7) \\
\hline \multicolumn{9}{|c|}{ Number of chronic comorbidities (\%) } \\
\hline 0 & $\begin{array}{l}58323 \\
(85.6)\end{array}$ & $\begin{array}{l}13155 \\
(88.2)\end{array}$ & $\begin{array}{l}13086 \\
(86.6)\end{array}$ & $\begin{array}{l}12330 \\
(86.0)\end{array}$ & $\begin{array}{l}11292 \\
(84.2)\end{array}$ & $8460(81.5)$ & $39959(68.5)$ & $18364(31.5)$ \\
\hline 1 & $7849(11.5)$ & $1468(9.8)$ & $1628(10.8)$ & $1597(11.1)$ & $1674(12.5)$ & $1482(14.3)$ & $4568(58.2)$ & 3281 (41.8) \\
\hline $2+$ & $1993(2.9)$ & $292(2.0)$ & $398(2.6)$ & $412(2.9)$ & $447(3.3)$ & $444(4.3)$ & $805(40.4)$ & $1188(59.6)$ \\
\hline \multicolumn{9}{|c|}{ Number of acute comorbidities (\%) } \\
\hline 0 & $\begin{array}{l}56534 \\
(82.9)\end{array}$ & $\begin{array}{l}12767 \\
(85.6)\end{array}$ & $\begin{array}{l}12716 \\
(84.2)\end{array}$ & $\begin{array}{l}11917 \\
(83.1)\end{array}$ & $\begin{array}{l}10925 \\
(81.5)\end{array}$ & 8209 (79) & 38371 (67.9) & $18163(32.1)$ \\
\hline 1 & $9565(14)$ & $1792(12.0)$ & $2010(13.3)$ & $2013(14.0)$ & $2018(15.1)$ & $1732(16.7)$ & $5920(61.9)$ & $3645(38.1)$ \\
\hline $2+$ & $2066(3)$ & $356(2.4)$ & $386(2.6)$ & $409(2.9)$ & $470(3.5)$ & $445(4.3)$ & $1041(50.4)$ & $1025(49.6)$ \\
\hline \multicolumn{9}{|c|}{ Obesity at diagnosis (\%) } \\
\hline No & $\begin{array}{l}67194 \\
(98.6)\end{array}$ & $\begin{array}{l}14776 \\
(99.1)\end{array}$ & $\begin{array}{l}14930 \\
(98.8)\end{array}$ & $\begin{array}{l}14111 \\
(98.4)\end{array}$ & $\begin{array}{l}13185 \\
(98.3)\end{array}$ & $\begin{array}{l}10192 \\
(98.1)\end{array}$ & $44609(66.4)$ & $22585(33.6)$ \\
\hline Yes & $971(1.4)$ & $139(0.9)$ & $182(1.2)$ & $228(1.6)$ & $228(1.7)$ & $194(1.9)$ & $723(74.5)$ & $248(25.5)$ \\
\hline
\end{tabular}

Abbreviations: G, tumour grade; IQR, interquartile range; SES, socioeconomic status.

Table 2 Odds ratios of not receiving major resection by logistic regression, imputed data ( $n=68$ 165) 


\begin{tabular}{|c|c|c|c|c|c|c|}
\hline & \multicolumn{3}{|c|}{ Bivariable analysis } & \multicolumn{3}{|c|}{ Multivariable analysis } \\
\hline & $\mathrm{OR}^{*}$ & $95 \% \mathrm{Cl}$ & p-value ${ }^{\dagger}$ & Adjusted OR** & $95 \% \mathrm{Cl}$ & p-value \\
\hline \multicolumn{7}{|l|}{ SES } \\
\hline 1 (affluent) & \multicolumn{2}{|l|}{ Reference } & \multirow[t]{5}{*}{$<0.001^{\ddagger}$} & Reference & & \multirow[t]{5}{*}{$0.013^{\ddagger}$} \\
\hline 2 & 1.03 & $(0.98-1.08)$ & & 0.98 & $(0.92-1.04)$ & \\
\hline 3 & 1.08 & $(1.03-1.13)$ & & 1.01 & $(0.95-1.07)$ & \\
\hline 4 & 1.14 & $(1.08-1.20)$ & & 1.04 & $(0.98-1.11)$ & \\
\hline 5 (deprived) & 1.15 & $(1.09-1.22)$ & & 1.07 & $(1.00-1.15)$ & \\
\hline \multicolumn{7}{|l|}{ Sex } \\
\hline Male & \multicolumn{2}{|l|}{ Reference } & \multirow[t]{2}{*}{0.99} & \multicolumn{2}{|l|}{ Reference } & \multirow[t]{2}{*}{0.008} \\
\hline Female & 1.00 & $(0.97-1.03)$ & & 0.94 & $(0.90-0.98)$ & \\
\hline \multicolumn{7}{|l|}{ Age group } \\
\hline$<65$ & \multicolumn{2}{|l|}{ Reference } & \multirow[t]{3}{*}{$<0.001^{\ddagger}$} & Reference & & \multirow[t]{3}{*}{$<0.001^{\ddagger}$} \\
\hline 65 to 80 & 1.01 & $(0.97-1.05)$ & & 1.09 & $(1.04-1.15)$ & \\
\hline $80<$ & 2.43 & $(2.32-2.54)$ & & 3.17 & $(2.98-3.36)$ & \\
\hline \multicolumn{7}{|l|}{ Year of diagnosis } \\
\hline 2010 & \multicolumn{3}{|l|}{ Reference } & \multicolumn{3}{|l|}{ Reference } \\
\hline 2011 & 1.04 & $(1.00-1.08)$ & 0.06 & 1.17 & $(1.10-1.23)$ & $<0.001$ \\
\hline 2012 & 1.06 & $(1.02-1.10)$ & 0.004 & 1.29 & $(1.22-1.36)$ & $<0.001$ \\
\hline 2013 & 1.14 & $(1.07-1.21)$ & $<0.001$ & 1.40 & $(1.29-1.52)$ & $<0.001$ \\
\hline \multicolumn{7}{|l|}{ Cancer site $\#$} \\
\hline Right-sided colon & \multicolumn{3}{|l|}{ Reference } & \multicolumn{3}{|l|}{ Reference } \\
\hline Transverse colon & 1.00 & $(0.94-1.06)$ & 0.96 & 1.11 & $(1.04-1.19)$ & 0.003 \\
\hline Left-sided colon & 1.40 & $(1.35-1.45)$ & $<0.001$ & 1.89 & $(1.80-1.98)$ & $<0.001$ \\
\hline Overlapping or unspecified & 5.49 & $(5.17-5.84)$ & $<0.001$ & 4.73 & $(4.36-5.13)$ & $<0.001$ \\
\hline \multicolumn{7}{|l|}{ Stage at diagnosis (imputed) } \\
\hline I & \multicolumn{2}{|l|}{ Reference } & \multirow[t]{4}{*}{$<0.001^{\ddagger}$} & Reference & & \multirow[t]{4}{*}{$<0.001^{\ddagger}$} \\
\hline II & 0.24 & $(0.22-0.26)$ & & 0.22 & $(0.18-0.27)$ & \\
\hline III & 0.35 & $(0.32-0.39)$ & & 0.33 & $(0.28-0.40)$ & \\
\hline IV & 4.26 & $(3.99-4.55)$ & & 4.77 & $(4.14-5.50)$ & \\
\hline
\end{tabular}

Continued from Table 2 


\begin{tabular}{|c|c|c|c|c|c|c|}
\hline & \multicolumn{3}{|c|}{ Bivariable analysis } & \multicolumn{3}{|c|}{ Multivariable analysis } \\
\hline & $\mathrm{OR}^{*}$ & $95 \% \mathrm{Cl}$ & p-value ${ }^{\dagger}$ & Adjusted OR** & $95 \% \mathrm{Cl}$ & p-value ${ }^{\dagger}$ \\
\hline \multicolumn{7}{|l|}{ Histology (imputed) } \\
\hline Adenocarcinoma & \multicolumn{2}{|l|}{ Reference } & \multirow[t]{2}{*}{0.007} & & & \\
\hline Non-adenocarcinoma & 1.26 & $(1.07-1.50)$ & & & & \\
\hline \multicolumn{7}{|l|}{ Tumour grade (imputed) } \\
\hline $\mathrm{G} 1, \mathrm{G} 2$ & \multicolumn{2}{|l|}{ Reference } & \multirow[t]{2}{*}{$<0.001$} & \multicolumn{2}{|l|}{ Reference } & $<0.001$ \\
\hline G3, G4 & 1.54 & $(1.46-1.63)$ & & 1.23 & $(1.15-1.33)$ & \\
\hline \multicolumn{7}{|c|}{ Emergency presentation (imputed) } \\
\hline No & \multicolumn{2}{|l|}{ Reference } & \multirow[t]{2}{*}{$<0.001$} & \multicolumn{2}{|l|}{ Reference } & $<0.001$ \\
\hline Yes & 1.09 & $(1.05-1.14)$ & & 0.61 & $(0.58-0.64)$ & \\
\hline \multicolumn{7}{|c|}{ Number of chronic comorbidities } \\
\hline 0 & \multicolumn{2}{|l|}{ Reference } & \multirow[t]{3}{*}{$<0.001^{\ddagger}$} & \multicolumn{2}{|l|}{ Reference } & $<0.001^{\ddagger}$ \\
\hline 1 & 1.55 & $(1.48-1.63)$ & & 1.61 & $(1.51-1.71)$ & \\
\hline $2+$ & 3.18 & $(2.90-3.48)$ & & 3.84 & $(3.39-4.35)$ & \\
\hline \multicolumn{7}{|c|}{ Number of acute comorbidities } \\
\hline 0 & \multicolumn{2}{|l|}{ Reference } & \multirow[t]{3}{*}{$<0.001^{\ddagger}$} & \multicolumn{2}{|l|}{ Reference } & $<0.001^{\ddagger}$ \\
\hline 1 & 1.29 & $(1.24-1.35)$ & & 1.28 & $(1.20-1.36)$ & \\
\hline $2+$ & 2.06 & $(1.89-2.25)$ & & 2.04 & $(1.80-2.31)$ & \\
\hline \multicolumn{7}{|l|}{ Obesity at diagnosis } \\
\hline No & \multicolumn{2}{|l|}{ Reference } & \multirow[t]{2}{*}{$<0.001$} & \multicolumn{2}{|l|}{ Reference } & 0.001 \\
\hline Yes & 0.67 & $(0.58-0.77)$ & & 0.73 & $(0.61-0.88)$ & \\
\hline
\end{tabular}

Abbreviations: $95 \% \mathrm{Cl}$, 95\% confidence interval; OR, odds ratio; SES, socioeconomic status. * Adjusted for SES in all variables. ** All variables are mutually adjusted. For SES only, adjusted ORs are shown without interaction between SES and stage. For other variables, interaction between SES and stage is adjusted. \# Right-sided colon includes the ascending colon, hepatic flexure and caecum. Transverse colon includes the transverse colon and splenic flexure. Left-sided colon includes the descending colon and sigmoid colon. † P-value of Wald test. ‡ P-value of Wald test for trend.

Table 3 Adjusted stage-specific odds ratios of not receiving major resection, imputed data ( $\mathrm{n}=68$ 165) 


\begin{tabular}{|c|c|c|c|}
\hline & Adjusted OR & $95 \% \mathrm{Cl}$ & p-value \\
\hline \multicolumn{4}{|l|}{ Stage I } \\
\hline SES 1 (affluent) & Reference & & \multirow[t]{5}{*}{0.41} \\
\hline 2 & 0.89 & $(0.75-1.04)$ & \\
\hline 3 & 0.99 & $(0.84-1.17)$ & \\
\hline 4 & 1.03 & $(0.87-1.22)$ & \\
\hline 5 (deprived) & 1.01 & $(0.84-1.22)$ & \\
\hline \multicolumn{4}{|l|}{ Stage II } \\
\hline SES 1 & Reference & & \multirow[t]{5}{*}{0.15} \\
\hline 2 & 0.96 & $(0.79-1.17)$ & \\
\hline 3 & 1.01 & $(0.84-1.21)$ & \\
\hline 4 & 1.08 & $(0.91-1.29)$ & \\
\hline 5 & 1.10 & $(0.90-1.35)$ & \\
\hline \multicolumn{4}{|l|}{ Stage III } \\
\hline SES 1 & Reference & & \multirow[t]{5}{*}{0.06} \\
\hline 2 & 1.03 & $(0.87-1.22)$ & \\
\hline 3 & 1.02 & $(0.87-1.20)$ & \\
\hline 4 & 1.13 & $(0.95-1.33)$ & \\
\hline 5 & 1.15 & $(0.97-1.37)$ & \\
\hline \multicolumn{4}{|l|}{ Stage IV } \\
\hline SES 1 & Reference & & \multirow[t]{5}{*}{0.40} \\
\hline 2 & 1.00 & $(0.91-1.10)$ & \\
\hline 3 & 1.01 & $(0.92-1.11)$ & \\
\hline 4 & 1.00 & $(0.91-1.10)$ & \\
\hline 5 & 1.06 & $(0.95-1.17)$ & \\
\hline
\end{tabular}

Interaction between SES and stage is added to the multivariable logistic regression model. Abbreviations: 95\% Cl, 95\% confidence interval; OR, odds ratio; SES, socioeconomic status. All p-values are of Wald test for trend. Adjusted for sex, age, year of diagnosis, site, tumour grade§, emergency presentation§, number of chronic and acute comorbidities and obesity (§: multiply imputed).

Table 4 Percentage of patients comparing elective/urgent surgery and with resection within/more than 31 days by SES 


\begin{tabular}{|c|c|c|c|c|c|c|c|}
\hline & & SES & & & & & \multirow[t]{3}{*}{ p-value } \\
\hline & \multirow[t]{2}{*}{ Total (\%) } & 1 & \multirow[t]{2}{*}{2} & \multirow[t]{2}{*}{3} & \multirow[t]{2}{*}{4} & 5 & \\
\hline & & (affluent) & & & & (deprived) & \\
\hline \multicolumn{8}{|c|}{ Received elective or urgent surgery } \\
\hline \multirow[t]{2}{*}{ Elective } & 28452 & 6551 & 6565 & 5966 & 5322 & 4048 & \multirow[t]{4}{*}{$<0.001$} \\
\hline & $(62.8)$ & $(64.6)$ & $(64.4)$ & $(62.7)$ & $(60.9)$ & $(60.1)$ & \\
\hline \multirow[t]{2}{*}{ Urgent } & 16880 & 3595 & 3632 & 3554 & 3414 & 2685 & \\
\hline & $(37.2)$ & $(35.4)$ & $(35.6)$ & $(37.3)$ & $(39.1)$ & $(39.9)$ & \\
\hline \multicolumn{8}{|c|}{ Received resection for the primary lesion within $\mathbf{3 1}$ days of diagnosis } \\
\hline \multirow[t]{2}{*}{ within 31 days } & 27436 & 6058 & 6008 & 5720 & 5365 & 4285 & \multirow[t]{4}{*}{$<0.001$} \\
\hline & $(60.5)$ & $(59.7)$ & $(58.9)$ & $(60.1)$ & $(61.4)$ & $(63.6)$ & \\
\hline \multirow[t]{2}{*}{ more than 31 days } & 17896 & 4088 & 4189 & 3800 & 3371 & 2448 & \\
\hline & $(39.5)$ & $(40.3)$ & $(41.1)$ & $(39.9)$ & $(38.6)$ & $(36.4)$ & \\
\hline \multicolumn{8}{|c|}{ Received resection for the primary lesion within 31 days of diagnosis for patients with elective surgery only } \\
\hline \multirow[t]{2}{*}{ within 31 days } & 10556 & 2463 & 2376 & 2166 & 1951 & 1600 & \multirow[t]{4}{*}{0.004} \\
\hline & $(37.1)$ & $(37.6)$ & $(36.2)$ & $(36.3)$ & $(36.7)$ & $(39.5)$ & \\
\hline \multirow[t]{2}{*}{ more than 31 days } & 17896 & 4088 & 4189 & 3800 & 3371 & 2448 & \\
\hline & $(62.9)$ & $(62.4)$ & $(63.8)$ & $(63.7)$ & (63.3) & $(60.5)$ & \\
\hline
\end{tabular}

Abbreviations: SES, socioeconomic status. P-value of chi square test for trend.

Table 5 Reference number of days and ratios for time from diagnosis to major resection 


\begin{tabular}{|c|c|c|c|c|c|c|}
\hline & \multicolumn{3}{|c|}{ Bivariable analysis } & \multicolumn{3}{|c|}{ Multivariable analysis } \\
\hline & $e^{\beta}$ & $95 \% \mathrm{Cl}$ & p-value ${ }^{\dagger}$ & Adjusted $\mathrm{e}^{\beta}$ & $95 \% \mathrm{Cl}$ & p-value ${ }^{\dagger}$ \\
\hline \multicolumn{7}{|l|}{ SES } \\
\hline Reference (geometric mean) days in SES 1 & 36.3 & $(35.8-36.8)$ & & 38.3 & $(37.3-39.2)$ & \\
\hline 1 (affluent) & \multicolumn{2}{|l|}{ Reference } & \multirow[t]{5}{*}{$0.98^{\ddagger}$} & Reference & & \multirow{5}{*}{$0.49^{\ddagger}$} \\
\hline 2 & 1.01 & $(0.99-1.02)$ & & 1.00 & $(0.98-1.02)$ & \\
\hline 3 & 1.01 & $(0.99-1.03)$ & & 1.01 & $(0.99-1.03)$ & \\
\hline 4 & 1.02 & $(1.00-1.04)$ & & 1.02 & $(1.00-1.04)$ & \\
\hline 5 (deprived) & 0.99 & $(0.97-1.01)$ & & 0.99 & $(0.97-1.02)$ & \\
\hline \multicolumn{7}{|l|}{ Sex } \\
\hline Male & \multicolumn{2}{|l|}{ Reference } & \multirow[t]{2}{*}{$<0.001$} & \multicolumn{2}{|l|}{ Reference } & \multirow[t]{2}{*}{$<0.001$} \\
\hline Female & 0.96 & $(0.95-0.97)$ & & 0.97 & $(0.96-0.98)$ & \\
\hline \multicolumn{7}{|l|}{ Age group } \\
\hline Median age at diagnosis & 72.6 & & & & & \\
\hline Age as linear (every +10 years) & 1.01 & $(1.01-1.02)$ & $<0.001$ & 1.02 & $(1.01-1.03)$ & $<0.001$ \\
\hline Age as quadratic term & †† & & $<0.001^{\dagger \dagger}$ & †† & & NA \\
\hline \multicolumn{7}{|l|}{ Year of diagnosis } \\
\hline 2010 & Reference & & & & & \\
\hline 2011 & 1.01 & $(1.00-1.03)$ & 0.16 & & & \\
\hline 2012 & 1.00 & $(0.98-1.01)$ & 0.81 & & & \\
\hline 2013 & 1.01 & $(0.98-1.04)$ & 0.48 & & & \\
\hline \multicolumn{7}{|l|}{ Cancer site } \\
\hline Right-sided colon & Reference & & & Reference & & \\
\hline Transverse colon & 1.00 & $(0.98-1.02)$ & 0.78 & 1.00 & $(0.98-1.02)$ & 0.88 \\
\hline Left-sided colon & 1.14 & $(1.12-1.15)$ & $<0.001$ & 1.13 & $(1.11-1.14)$ & $<0.001$ \\
\hline Overlapping or unspecified & 1.09 & $(1.05-1.13)$ & $<0.001$ & 1.09 & $(1.05-1.13)$ & $<0.001$ \\
\hline \multicolumn{7}{|l|}{ Stage at diagnosis (imputed) } \\
\hline I & Reference & & $<0.001^{\ddagger}$ & Reference & & $0.06^{\ddagger}$ \\
\hline ॥ & 0.87 & $(0.85-0.89)$ & & 0.89 & $(0.85-0.93)$ & \\
\hline III & 0.88 & $(0.86-0.90)$ & & 0.91 & $(0.87-0.96)$ & \\
\hline IV & 0.89 & $(0.86-0.91)$ & & 0.93 & $(0.88-0.98)$ & \\
\hline
\end{tabular}

Continued from Table 5 


\begin{tabular}{|c|c|c|c|c|c|c|}
\hline & \multicolumn{3}{|c|}{ Bivariable analysis } & \multicolumn{3}{|c|}{ Multivariable analysis } \\
\hline & $e^{\beta}$ & $95 \% \mathrm{Cl}$ & p-value ${ }^{\dagger}$ & Adjusted $\mathrm{e}^{\beta}$ & $95 \% \mathrm{Cl}$ & p-value ${ }^{\dagger}$ \\
\hline \multicolumn{7}{|l|}{ Histology (imputed) } \\
\hline Adenocarcinoma & \multicolumn{2}{|l|}{ Reference } & \multirow[t]{2}{*}{0.04} & \multicolumn{2}{|l|}{ Reference } & \multirow[t]{2}{*}{0.001} \\
\hline Non-adenocarcinoma & 1.10 & $(1.01-1.20)$ & & 1.16 & $(1.07-1.27)$ & \\
\hline \multicolumn{7}{|l|}{ Tumour grade (imputed) } \\
\hline $\mathrm{G} 1, \mathrm{G} 2$ & \multicolumn{2}{|l|}{ Reference } & \multirow[t]{2}{*}{$<0.001$} & \multicolumn{2}{|l|}{ Reference } & \multirow[t]{2}{*}{$<0.001$} \\
\hline G3, G4 & 0.93 & $(0.91-0.95)$ & & 0.97 & $(0.95-0.98)$ & \\
\hline \multicolumn{7}{|c|}{ Emergency presentation (imputed) } \\
\hline No & \multicolumn{2}{|l|}{ Reference } & \multirow[t]{2}{*}{$<0.001$} & \multicolumn{2}{|l|}{ Reference } & \multirow[t]{2}{*}{$<0.001$} \\
\hline Yes & 0.87 & $(0.85-0.88)$ & & 0.87 & $(0.85-0.89)$ & \\
\hline \multicolumn{7}{|c|}{ Number of chronic comorbidities } \\
\hline 0 & \multicolumn{2}{|l|}{ Reference } & \multirow[t]{3}{*}{$<0.001^{\ddagger}$} & Reference & & \multirow[t]{3}{*}{$<0.001^{\ddagger}$} \\
\hline 1 & 1.06 & $(1.04-1.09)$ & & 1.07 & $(1.04-1.09)$ & \\
\hline $2+$ & 1.13 & $(1.07-1.19)$ & & 1.14 & $(1.08-1.20)$ & \\
\hline \multicolumn{7}{|c|}{ Number of acute comorbidities } \\
\hline 0 & \multicolumn{2}{|l|}{ Reference } & \multirow{3}{*}{$<0.001^{\ddagger}$} & Reference & & \multirow[t]{3}{*}{$<0.001^{\ddagger}$} \\
\hline 1 & 1.03 & $(1.01-1.05)$ & & 1.05 & $(1.02-1.07)$ & \\
\hline $2+$ & 1.11 & $(1.05-1.18)$ & & 1.16 & $(1.09-1.22)$ & \\
\hline \multicolumn{7}{|l|}{ Obesity at diagnosis } \\
\hline No & \multicolumn{2}{|l|}{ Reference } & \multirow[t]{2}{*}{0.05} & & & \\
\hline Yes & 1.07 & $(1.00-1.14)$ & & & & \\
\hline
\end{tabular}

The linear regression model includes patients with elective surgery only using multiply imputed data ( $\mathrm{n}=28$ 452). Abbreviations: $95 \% \mathrm{Cl}, 95 \%$ confidence interval; NA, not applicable; SD, standard deviation; SES, socioeconomic status. * Adjusted for SES in all variables. ** All variables are mutually adjusted. For SES only, days and adjusted ratios are shown without interaction between SES and stage. For other variables, interaction between SES and stage is adjusted. \# Right-sided colon includes the ascending colon, hepatic flexure and caecum. Transverse colon includes the transverse colon and splenic flexure. Left-sided colon includes the descending colon and sigmoid colon. † P-value of the null hypothesis that the coefficient $(\beta)$ is 0 ( $\left.e^{\beta}=1\right)$ when all other variables were set at the reference group. $¥ P$-value of Wald test for trend. †+ When age is put as a quadratic term, in bivariable analysis, log(days) is derived from a(constant) + $\beta_{1}(0$ in SES $=1)+\beta_{2}($ age-mean age $)+\beta_{3}(\text { age-mean age })^{2}$.

Table 6 Adjusted stage-specific ratios and reference number of days from diagnosis to major resection 


\begin{tabular}{|c|c|c|c|}
\hline & Adjusted ratio & $95 \% \mathrm{Cl}$ & p-value \\
\hline \multicolumn{4}{|l|}{ Stage I } \\
\hline Reference days in SES 1 & 38.2 & $(36.8-39.7)$ & \\
\hline SES 1 (affluent) & Reference & & \multirow[t]{5}{*}{0.25} \\
\hline 2 & 1.00 & $(0.95-1.05)$ & \\
\hline 3 & 1.01 & $(0.96-1.07)$ & \\
\hline 4 & 1.01 & $(0.95-1.06)$ & \\
\hline 5 (deprived) & 1.04 & $(0.97-1.10)$ & \\
\hline \multicolumn{4}{|l|}{ Stage II } \\
\hline Reference days in SES 1 & 33.9 & $(33.1-34.8)$ & \\
\hline SES 1 & Reference & & \multirow[t]{5}{*}{0.64} \\
\hline 2 & 1.02 & $(0.98-1.05)$ & \\
\hline 3 & 1.03 & $(1.00-1.07)$ & \\
\hline 4 & 1.04 & $(1.00-1.08)$ & \\
\hline 5 & 0.99 & $(0.95-1.03)$ & \\
\hline \multicolumn{4}{|l|}{ Stage III } \\
\hline Reference days in SES 1 & 34.9 & $(33.9-36.0)$ & \\
\hline SES 1 & Reference & & \multirow[t]{5}{*}{0.62} \\
\hline 2 & 0.98 & $(0.95-1.02)$ & \\
\hline 3 & 1.00 & $(0.97-1.04)$ & \\
\hline 4 & 1.01 & $(0.97-1.05)$ & \\
\hline 5 & 1.00 & $(0.96-1.04)$ & \\
\hline \multicolumn{4}{|l|}{ Stage IV } \\
\hline Reference days in SES 1 & 35.5 & $(34.1-37.0)$ & \\
\hline SES 1 & Reference & & \multirow[t]{5}{*}{0.30} \\
\hline 2 & 1.02 & $(0.97-1.08)$ & \\
\hline 3 & 0.99 & $(0.93-1.05)$ & \\
\hline 4 & 1.03 & $(0.97-1.09)$ & \\
\hline 5 & 0.95 & $(0.90-1.01)$ & \\
\hline
\end{tabular}

Interaction between SES and stage is added to the multivariable linear regression model. The multiply imputed data include patients with elective surgery only ( $n=28$ 452). Abbreviations: 95\% Cl, 95\% confidence interval; SES, socioeconomic status. All p-values are of Wald test for trend. Adjusted for sex, age, site, histology§, tumour grade§, emergency presentation§, number of chronic and acute comorbidities (§: multiply imputed).

\section{Supplementary Files}

This is a list of supplementary files associated with this preprint. Click to download.

- Additionalfile6.pdf

- Additionalfile4.pdf

- Additionalfile5.pdf

- Additionalfile3.pdf

- Additionalfile1.pdf

- Additionalfile2.pdf

- Additionalfile7.pdf 